\title{
Impact of Local Environment on Cooling Island Effect of Water Body: Case Study of Changsha, China
}

\author{
Xinyi Qiu, ${ }^{1}$ Sung-Ho Kil, ${ }^{*}$ and Chan Park ${ }^{2}$ \\ ${ }^{1}$ Department of Ecological Landscape Architecture Design, Kangwon National University, \\ Gangwon-Dae-Hak-Gil 1, Chuncheon, Ganwondo 24341, South Korea \\ ${ }^{2}$ Department of Landscape Architecture, University of Seoul, Seoulsilipdaero 163, Seoul 02504, South Korea
}

(Received July 27, 2021; accepted September 24, 2021)

Keywords: local environment, water cooling island effect, thermal environment, remote sensing

The deterioration of the urban thermal environment poses multiple threats to residents' health and the ecological environment. The impact of the local environment on the water cooling island (WCI) effect is complex and non-negligible. In this study, 21 water bodies in Changsha, China, were selected to reveal the impact of the local environment on the WCI effect. The results showed that the average cooling distance (WCI_D), cooling magnitude (WCI_M), and cooling gradient (WCI_G) of the water bodies are approximately $0.31 \mathrm{~km}, 2.36{ }^{\circ} \mathrm{C}$, and $7.61{ }^{\circ} \mathrm{C} / \mathrm{km}$, respectively. The WCI effect changes with the type of land cover surrounding the water body: the greatest WCI effect occurs when the water body is surrounded by built-up land, followed by bare land, forest, and cropland. Shannon's diversity index (SHDI) was the factor with the greatest effect on WCI_D and WCI_G, while the landscape shape index (LSI) had the greatest effect on WCI_M. The wind direction has a significant impact on WCI_D and WCI_M. The influence of the wind direction on the WCI effect is obvious, e.g., the impact of prevailing wind in the downwind direction on the WCI effect is larger than that in the upwind direction, where WCI_D and WCI_M in the downwind direction were $0.15 \mathrm{~km}$ and $0.24{ }^{\circ} \mathrm{C}$ larger than those in the upwind direction, respectively.

\section{Introduction}

China has been undergoing rapid urbanization over the past 40 years. Its urban regions cover an area up to 12 times larger than that in 1981. ${ }^{(1)}$ According to the National Bureau of Statistics of China (2015), the urbanization rate of China is expected to reach $70 \%$ by 2030 . $^{(2)}$ The rapid development has led to the degradation of the urban thermal environment with adverse effects on public health and the ecological environment.

Water bodies and green space in urban areas as urban cooling islands have been shown academically to play important roles in mitigating urban heat island (UHI) effects. ${ }^{(3-6)}$ The cooling island effect refers to the phenomenon that the temperature in the area is obviously lower than that in the surrounding area. Owing to the higher heat capacity and evapotranspiration, ${ }^{(7,8)}$ the water cooling island (WCI) effect is much greater than the cooling effect of green space. ${ }^{(9)}$

${ }^{*}$ Corresponding author: e-mail: sunghokil@kangwon.ac.kr https://doi.org/10.18494/SAM.2021.3570 
Urban water bodies (such as rivers, lakes, and streams) play an important part in the regulation of local microclimate and ecological services, ${ }^{(10)}$ improve outdoor thermal comfort, and reduce the ambient temperature of the surrounding environment, and are becoming a crucial solution to cope with climate change and improve the urban thermal environment. ${ }^{(11,12)}$

The WCI effect mainly depends on the water body size, shape, surrounding vegetation coverage, architectural features, and atmospheric circulation (such as the wind direction and speed). ${ }^{(13,14)}$ In previous research, similarly to the description of UHI intensity, the WCI effect was described from three aspects: the cooling distance (WCI_D), cooling magnitude (WCI_M), and cooling gradient (WCI_G). ${ }^{(15,16)}$

Many researchers have conducted quantitative analysis on the WCI effect. Syafii et al. found that even a $4 \mathrm{~m}^{2}$ pond can reduce the temperature in the surrounding area, ${ }^{(17)}$ while Saaroni and Ziv found that a pond of 4 ha could provide a cooling effect over a distance of $40 \mathrm{~m}$. ${ }^{(18)}$ Adams and Dove reported that a $35-\mathrm{m}$-wide river caused a drop of $1-1.5^{\circ} \mathrm{C}$ in the ambient temperature over a range of $30 \mathrm{~m} .{ }^{(19)}$ Sun and Chen conducted WCI research on 197 water bodies in Beijing and demonstrated that the mean amplitude and efficiency of the WCI were $0.54{ }^{\circ} \mathrm{C} / \mathrm{hm}$ and $1.76{ }^{\circ} \mathrm{C} / \mathrm{hm} / \mathrm{ha}$, respectively. ${ }^{(12)} \mathrm{Zeng}$ et al. found that $2 \mathrm{~km}^{2}$ water has the capability to cool the environment by $0.6^{\circ} \mathrm{C}$ over a range of $1 \mathrm{~km} .{ }^{(11)}$

In recent years, research on the mechanism of the WCI effect has gradually increased, mainly concentrating on the investigation of WCI_D, WCI_M, and the changes in the WCI effect caused by seasonal differences. However, there has been insufficient research on the impact of the local environment on the WCI effect, such as the changes in WCI_D and WCI_M caused by an upwind and downwind direction, or the difference due to different types of land cover.

In addition, some studies revealed the relationship between the landscape indexes of water bodies and the UHI effect, showing that the area, shape, connectivity, and density of the landscape have a major influence on the land surface temperature (LST). Appropriately designed water bodies can reduce the UHI effect. ${ }^{(20,21)}$ Therefore, how to improve the cooling effect of water bodies in urban areas with a high population concentration and high land utilization has strong practical significance.

The objective of this study is to discuss the impact of the local environment on the WCI effect. To achieve this goal, 21 water bodies in Changsha with area $>1$ ha and no other water body within $1 \mathrm{~km}$ were selected. First, the WCI effect of each water body was comprehensively determined. Second, the influence of the type of land cover on the WCI effect was examined. Finally, the relationship between the key landscape indicators and the WCI effect was assessed by Pearson correlation coefficient analysis and stepwise regression analysis, and the influence of the wind direction was also considered. The results of this study provide useful suggestions for promoting the healthy and sustainable development of the urban ecology and for urban managers designing and maintaining urban water bodies.

\section{Study Area}

Changsha is the capital of Hunan Province, located in the mid-central region of China, spanning $111^{\circ} 53^{\prime}-114^{\circ} 15^{\prime} \mathrm{E}$ and $27^{\circ} 51^{\prime}-28^{\circ} 40^{\prime} \mathrm{N}$ (Fig. 1). As one of the ten hottest cities in China, 


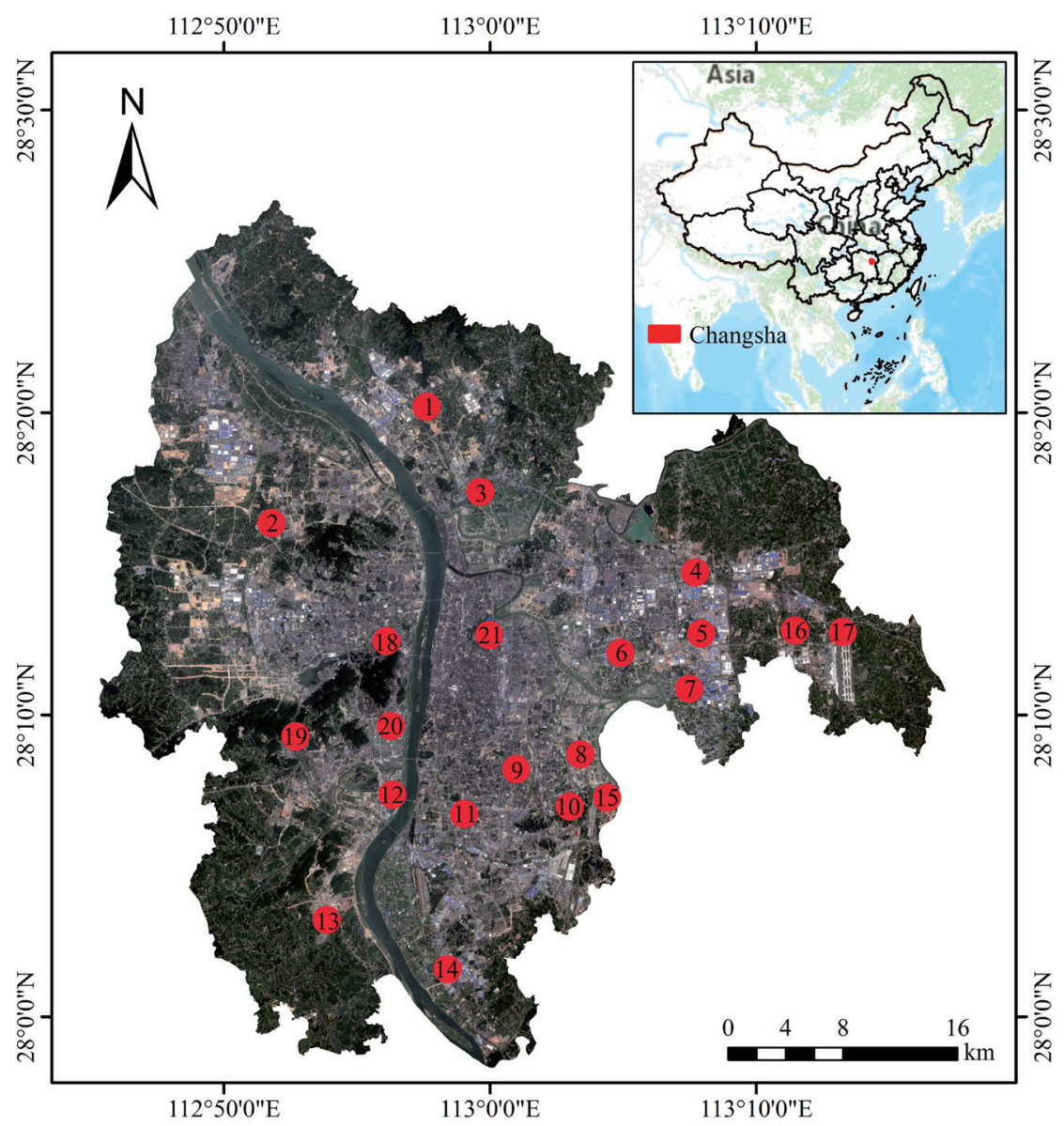

Fig. 1. (Color online) Location of study area, where numbers in red circles present the locations of 21 water bodies.

the summer in Changsha is long with high temperatures. ${ }^{(22)}$ Rainfall is abundant owing to the humid subtropical monsoon climate. The annual rainfall of the city is approximately $1500 \mathrm{~mm}$. The city's average air temperature in July exceeds $29.4{ }^{\circ} \mathrm{C}$ with a rainfall of $139.75 \mathrm{~mm} .{ }^{(23)} \mathrm{In}$ the past decades, Changsha has undergone significant urbanization and now has an urbanization rate of $77.59 \%$. According to the Seventh National Census of Hunan Province, the city's population reached approximately 10 million in 2020 with the built-up area reaching $40.89 \%$ $\left(587.99 \mathrm{~km}^{2}\right)$. Rapid urbanization has resulted in the emergence of UHIs, and the average LST in the main urban zone is $2.59{ }^{\circ} \mathrm{C}$ higher than that in 1988 . The total area of water was $108.49 \mathrm{~km}^{2}$ in 2019, accounting for $7.91 \%$ of the total area in Changsha; however, this was $36.16 \mathrm{~km}^{2}(25 \%)$ lower than that in 1988. ${ }^{(24)}$

According to the results of land cover classification, there are a total of 162 water bodies in the study area, excluding rivers. To reduce the cross-effect of the WCI effect between various water bodies and take into account the spatial resolution of the Landsat 8 thermal IR band (100 m), 21 water bodies with areas larger than 1 ha and no other water bodies within $1 \mathrm{~km}$ were selected as the research objects. 


\section{Data and Methods}

\subsection{LST retrieval}

The LST, as a key factor affecting the near-surface air temperature and a useful index that can be obtained easily through remote sensing data, has been widely used in studies of urban thermal environments. The thermal infrared sensor (TIRS) images carried by the Satellite Landsat 8 were used to calculate the LST. The data were downloaded from the US Geological Survey (https://earthexplorer.usgs.gov/) and the acquisition date was August 17, 2019. The average air temperature for the date was $31.25{ }^{\circ} \mathrm{C}$, as obtained from China Meteorological Administration.

A single-band algorithm was adopted to retrieve the LST. This algorithm contains three basic algorithms: the radiative transfer equation, mono-window algorithm, and single-channel method. ${ }^{(25-28)}$ Considering the availability of Landsat data and the actual situation in the study area, the mono-window algorithm, which is the most commonly used method in Asia, ${ }^{(29,30)}$ was employed to retrieve the LST in this study.

The mono-window algorithm contains four input parameters: land surface emissivity, atmospheric transmissivity, brightness temperature, and average atmospheric temperature. All the constant parameters adopted in the algorithm were suitable for regions with a medium latitude in summer. The formulas of the mono-window algorithm used to obtain the LST $\left(T_{s}\right)$ can be expressed as

$$
\begin{gathered}
T_{S}=\left\{a(1-C-D)+[b(1-C-D)+C+D] T-D T_{a}\right\} / C, \\
C=\varepsilon \tau, \\
D=(1-\tau)[1+(1-\varepsilon) \tau], \\
\tau=1.0163-0.1330 \mathrm{w}, \\
T_{a}=16.0110+0.9262 T_{0}+273.15,
\end{gathered}
$$

where $T$ is the brightness temperature of the thermal IR band (band 10 of Landsat 8), $\varepsilon$ is the emissivity of the land surface, $\tau$ is the atmospheric transmissivity in band 10 for the atmosphere with total water vapor content $w\left(\mathrm{~g} \cdot \mathrm{cm}^{-2}\right)$ in the atmospheric column up to the sensor, $a=-62.7182$, and $b=0.4339, T_{a}$ is the average atmospheric temperature, $T_{0}$ is the atmospheric temperature provided by China Meteorological Data Service Center. ${ }^{(31)}$

\subsection{Land cover data}

The land cover data were obtained from Landsat 8 OLI images by a supervision classification method. Land cover was divided into five categories: built-up, bare land, water, cropland, and 
forest. Among them, cropland and forest are defined as green spaces. ${ }^{(32)}$ Notably, cropland in Changsha is mainly composed of rice paddy fields, which contain a large amount of water throughout the growing season, making it significantly different from typical cropland for growing wheat or corn in northern China.

To test the classification accuracy, 300 random points were selected and then interpreted using high-resolution spatial images from Google Earth. The validation results showed that the overall accuracy of the classification results was above $91.2 \%$.

\subsection{Definition of WCI effect}

Water can form a cooling island effect due to the specific heat capacity and evaporation at the water surface, leading to a temperature drop in the surrounding area. ${ }^{(33,34)}$ The characteristics of the WCI effect can be described by three aspects: the WCI_D, WCI_M, and WCI_G.

WCI_D is defined by the distance between the edge of the water body and the first turning point on the LST curve (Fig. 2). For each water body, the first turning point of the LST curve is selected manually as the point where the LST starts to decrease or reaches a relatively stable level. WCI_M is defined by the temperature difference between the water body and its first turning point. WCI_G is defined by the average temperature drop per unit distance, equaling WCI_M divided by WCI_D. ${ }^{(35)}$

Specifically, WCI_D is the most common indicator in existing studies. A larger WCI_D indicates a longer cooling distance, leading to a larger cooling range in the surrounding area. WCI_M is a supplementary indicator. There are two possible situations that increase WCI_M:

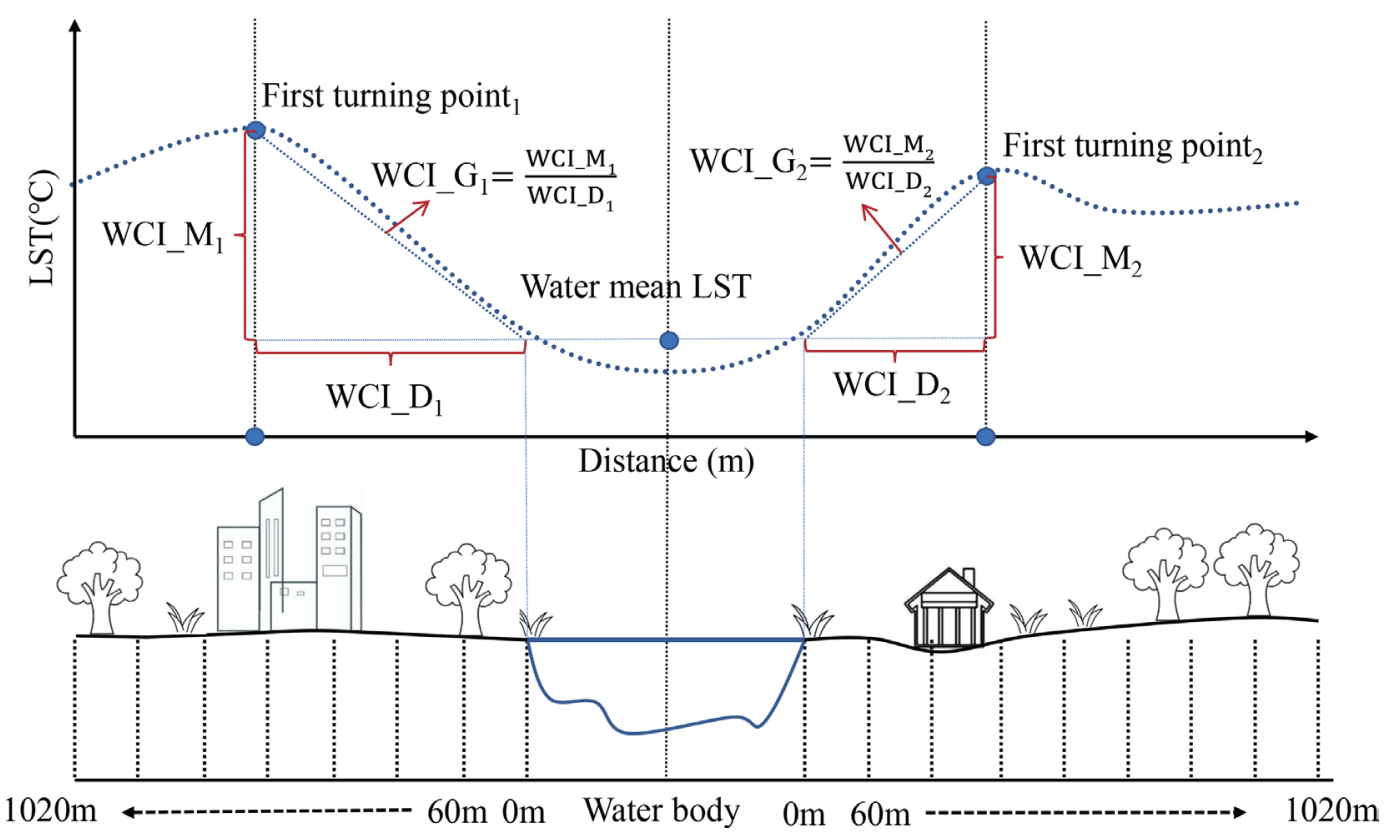

Fig. 2. (Color online) Illustration of WCI effects. 
(1) the water body is in a heat-concentrated area in the urban area, then an increase in the temperature difference between the water body and its surrounding area would lead to an increase in WCI_M; (2) the temperature in the water body decreases owing to the influence of the ambient environment, leading to an increase in WCI_M. Generally, a larger WCI_M indicates a better cooling effect. WCI_G is only a reference indictor, reflecting the cooling efficiency per unit distance, where a larger WCI_G indicates higher cooling efficiency.

To investigate the WCI effect of water bodies, 21 typical water bodies with area larger than 1 ha and no other water bodies within $1 \mathrm{~km}$ were selected as the research objects. Buffer zones were set up with a fixed interval surrounding the water bodies to extract the average LST and the landscape indexes in each buffer zone. The buffer interval $(60 \mathrm{~m})$ was twice the spatial resolution of Landsat 8 OLI images $(30 \mathrm{~m}$ ), and a distance of $1020 \mathrm{~m}$ (an integer multiple of $30 \mathrm{~m}$ ) was chosen as the furthest buffer distance on the basis of preliminary analysis results.

The spline function was adopted to increase the continuity of the LST variation with the distance. Specifically, the LST intervals were interpolated at intervals of $10 \mathrm{~m}$, then the average LST was calculated at intervals of $10 \mathrm{~m}$ from the center of the water body to the edge of the buffer zone to obtain the LST curve in the buffer zone (Fig. 2). Note that the average LST was extracted in each direction of the buffer zone or water body when discussing the influence of the wind direction on the WCI effects.

\subsection{Local environment indexes}

\subsubsection{Wind data and wind direction classification}

Generally, owing to the influence of the wind direction, the cooler air on the surface of a water body is more easily moved in the downward direction. In contrast, when the cooler air on the water surface moves in the upward direction, it is more susceptible to being blocked by a headwind.

The prevailing wind direction in Changsha in summer ranges from 146.26 to $191.25^{\circ}$, referred to as southeast wind and south wind, respectively. According to China Meteorological Administration, on the research date (August 17, 2019), the wind direction with the maximum wind speed was from 133 to $172^{\circ}$, corresponding to southeast wind and south wind, respectively, and the maximum wind speed was $3.6-3.8 \mathrm{~m} / \mathrm{s}$ (breezy).

To investigate the influence of the wind direction on the WCI effect, each water body and its surrounding buffers were divided into four directions. Starting from due north, every $90^{\circ}$ in the clockwise direction was assigned a direction, i.e., $0-90^{\circ}, 90-180^{\circ}, 180-270^{\circ}$, and $270-360^{\circ}$. The direction N-NE $\left(0-90^{\circ}\right)$ represents north wind and northeast wind; the direction E-SE $\left(90-180^{\circ}\right)$ represents east wind and southeast wind; the direction S-SW $\left(180-270^{\circ}\right)$ represents south wind and southwest wind; the direction W-NW $\left(270-360^{\circ}\right)$ represents west wind and northwest wind. Therefore, in this study, the directions E-SE and W-NW are defined as the upwind and downwind directions, respectively. ${ }^{(23)}$ 


\subsubsection{Landscape index of local environments}

To investigate the impact of the local environment surrounding water bodies on the WCI effect, we choose multiple landscape indicators that can represent the structural composition and spatial configuration around a single water body to quantify the environmental characteristics of the area around water bodies. ${ }^{(15,36,37)}$

From the aspect of the water body, two indictors, area and landscape shape index (LSI), were selected. From the landscape level, the patch density (PD) and Shannon's diversity index (SHDI) were selected to describe the overall characteristics of the surrounding environment within WCI_D. From the class level, the percent of landscape (PLAND), aggregation index (AI), largest patch index (LPI), and splitting index (SPLIT) were selected to describe the local characteristics of a certain land cover type (Table 1).

Table 1

Influencing factors of WCI used for this study.

\begin{tabular}{|c|c|c|}
\hline Index & Description & Equation \\
\hline LSI & $\begin{array}{l}\text { Complexity of shape of water body. Larger LSI indicates more irregular } \\
\text { shape, leading to larger contact surface between water body and } \\
\text { surrounding environment. }\end{array}$ & $L S I=\frac{D}{2 \sqrt{\pi \times W A}}$ \\
\hline PD & $\begin{array}{l}\text { Degree of differentiation or fragmentation of patches in landscape. Larger } \\
\text { PD represents greater fragmentation of landscape. }\end{array}$ & $P D=\frac{1}{A} \sum_{j=1}^{M} N_{i}$ \\
\hline SHDI & $\begin{array}{l}\text { Heterogeneity of landscape. Particularly sensitive to uneven distribution of } \\
\text { patch types in landscape. Larger SHDI represents more different types of } \\
\text { landscape, } \\
\text { richer land use, and greater fragmentation. }\end{array}$ & $S H D I=-\sum_{i=1}^{m}\left(p_{i} \times \ln p_{i}\right)$ \\
\hline PLAND_G & $\begin{array}{l}\text { Percentage of total area of green space (including cropland and forest) } \\
\text { in entire landscape area. Value near } 0 \text { indicates very rare patch type in } \\
\text { landscape. Value of } 100 \text { means entire landscape composed of one type of } \\
\text { patch. }\end{array}$ & $i_{-} P L A N D=\frac{A_{i}}{A} \times 100$ \\
\hline AI & $\begin{array}{l}\text { Degree of patch dispersion in landscape area. Larger AI means patches of } \\
\text { same type in landscape aggregate with each other; therefore, more compact } \\
\text { structure with higher connection degree and lower fragmentation within } \\
\text { patch. }\end{array}$ & $A I_{i}=\frac{g_{i i}}{\max \rightarrow g_{i i}} \times 100$ \\
\hline LPI & $\begin{array}{l}\text { Proportion of landscape area composed of largest patch. Reflects landscape } \\
\text { dominance. Value near } 0 \text { indicates that area of largest patch is small. Value } \\
\text { of } 100 \text { means entire landscape composed of only one type of patch. }\end{array}$ & $L P I=\frac{\max a_{i j}}{A} \times 100$ \\
\hline SPLIT & $\begin{array}{l}\text { Degree of separation of individual distribution of different patch numbers } \\
\text { in certain landscape type. Reflects aggregation and dispersion of patches. } \\
\text { Larger SPLIT indicates more scattered patches of this type and greater } \\
\text { fragmentation. }\end{array}$ & $S P L I T=\frac{A^{2}}{\sum_{j=1}^{n} a_{\mathrm{i} j}^{2}}$ \\
\hline
\end{tabular}

Note: $D$ and $W A$ : perimeter and area of water body, respectively, $M$ : total number of landscape element types, $A$ : total landscape area, $N_{i}$ : number of type $i$ patches of landscape elements, $p_{i}$ : area proportion of patch type $i$ in landscape, $m$ : number of patch types in landscape, $A_{i}$ : total area of type $i$ patches of landscape elements, $g_{i i}$ : number of common edges of patch type $i$ grid in landscape, $\max _{i i}$ : number of largest common edges of patch type $i$ grid in landscape, $a_{i j}$ : area of patch $i j$. 
Note that PLAND is only used for green space (PLAND_G), and the last three indexes are used for all land cover types. For simplicity, AI for built-up, bare land, cropland, and forest is denoted by AI_B, AI_BL, AI_C, and AI_F, respectively. LPI for built-up, bare land, cropland, and forest is denoted by LPI_B, LPI_BL, LPI_C, and LPI_F, respectively. SPLIT for built-up, bare land, cropland, and forest is denoted by SPLIT_B, SPLIT_BL, SPLIT_C, and SPLIT_F, respectively. All landscape indicators were calculated using Fragstats software (v4.2).

Pearson correlation coefficient analysis was used to quantify the relationship between the characteristics of water bodies and WCI effects. ${ }^{(38)}$ The variables with high or significant correlation values based on the results of Pearson correlation coefficient analysis were treated as potentially effective indicators of WCI effects. In addition, multiple stepwise regression, a common method to eliminate multicollinearity between factors and obtain optimal regression models, was employed to determine the key factors influencing the WCI effect.

The backward elimination procedure was used and alpha was set at 0.10 to decide whether to include the variables in the final models. ${ }^{(39)}$ Using the significance degree, the method can provide the explanatory power of the key factors and predict their relative importance for the WCI effect. P-values of less than 0.05 were considered statistically significant, while p-values of $0.05-0.1$ were considered suggestively statistically significant. ${ }^{(37)}$ All statistical analysis procedures were completed using Stata 14.

\section{Results and Discussion}

\subsection{WCI effects of 21 water bodies}

The area of the 21 water bodies in the study ranges from 1.01 to 56.83 ha, with the LSI ranging from 1.05 to 2.19 (Table 2). The LST of the water body has a negative correlation with the area and LSI of the water body; the LST tends to decrease with increasing size and complexity of the shape of the water body. This can be explained by the heat capacity and evaporation of the water body. On the one hand, a larger area with a higher water content contributes to a slower temperature increase, resulting in a lower LST of the water body. On the other hand, the complex shape of the water body increases the contact surface between the water body and the surrounding area, promoting the air flow and accelerating evaporation, thus reducing the LST of the water body.

WCI_D of the water body in the study is between 0.12 and $0.97 \mathrm{~km}$ with an average of 0.31 $\mathrm{km}$. The LST in the buffers increases with the distance from the water bodies and remains flat after reaching a certain distance (Fig. 3). All LST curves show similar rules for all types of land cover, which reveals that the WCI effect has a certain range of influence, and the water body has a certain cooling effect on all land cover types.

WCI_M of the water body in the study is between 0.64 and $4.16{ }^{\circ} \mathrm{C}$ with an average of $2.36^{\circ} \mathrm{C}$. Different land cover types show distinct differences in the cooling magnitude (Table 3), with the largest cooling magnitude occurring in built-up $\left(2.80{ }^{\circ} \mathrm{C}\right)$, followed by bare land $\left(2.01{ }^{\circ} \mathrm{C}\right)$, forest $\left(1.55^{\circ} \mathrm{C}\right)$, and cropland $\left(1.38{ }^{\circ} \mathrm{C}\right)$. Within the whole cooling distance, the maximum LST difference between the water body and built-up reached $5.09{ }^{\circ} \mathrm{C}$, followed by bare land $\left(3.6^{\circ} \mathrm{C}\right)$, forest $\left(2.92{ }^{\circ} \mathrm{C}\right)$, and cropland $\left(2.21^{\circ} \mathrm{C}\right)$. 
Table 2

WCI effect of water bodies.

\begin{tabular}{lrrcccc}
\hline Number & $\begin{array}{c}\text { Area } \\
(\mathrm{ha})\end{array}$ & LSI & $\begin{array}{c}\text { Water_LST } \\
\left({ }^{\circ} \mathrm{C}\right)\end{array}$ & $\begin{array}{c}\text { WCI_D } \\
(\mathrm{km})\end{array}$ & $\begin{array}{c}\text { WCI_M } \\
\left({ }^{\circ} \mathrm{C}\right)\end{array}$ & $\begin{array}{r}\text { WCI_G } \\
\left({ }^{\circ} \mathrm{C} / \mathrm{km}\right)\end{array}$ \\
\hline 1 & 2.89 & 1.34 & 28.40 & 0.37 & 2.69 & 7.27 \\
2 & 25.03 & 1.79 & 27.98 & 0.43 & 2.21 & 5.14 \\
3 & 13.26 & 1.56 & 28.18 & 0.20 & 2.79 & 13.95 \\
4 & 1.56 & 1.25 & 31.06 & 0.25 & 1.71 & 5.50 \\
5 & 2.36 & 1.32 & 30.89 & 0.23 & 3.7 & 17.45 \\
6 & 1.47 & 1.21 & 29.78 & 0.28 & 2.21 & 5.74 \\
7 & 2.16 & 1.21 & 28.84 & 0.27 & 1.80 & 6.62 \\
8 & 1.01 & 1.30 & 29.38 & 0.22 & 2.61 & 11.35 \\
9 & 1.80 & 1.07 & 29.84 & 0.18 & 2.36 & 13.18 \\
10 & 1.37 & 1.25 & 30.33 & 0.12 & 0.64 & 5.82 \\
11 & 3.40 & 1.98 & 30.46 & 0.18 & 0.98 & 5.51 \\
12 & 1.84 & 1.14 & 29.11 & 0.51 & 2.76 & 5.35 \\
13 & 5.62 & 1.05 & 28.45 & 0.21 & 2.57 & 12.24 \\
14 & 1.55 & 1.15 & 30.04 & 0.25 & 1.77 & 6.56 \\
15 & 1.37 & 1.08 & 29.38 & 0.27 & 1.21 & 4.48 \\
16 & 2.16 & 1.14 & 28.96 & 0.3 & 2.31 & 7.11 \\
17 & 23.67 & 1.31 & 27.98 & 0.54 & 3.20 & 5.93 \\
18 & 52.28 & 2.00 & 28.10 & 0.45 & 3.05 & 6.78 \\
19 & 2.58 & 1.16 & 29.01 & 0.14 & 1.10 & 7.97 \\
20 & 28.64 & 1.45 & 29.08 & 0.19 & 3.77 & 20.60 \\
21 & 56.83 & 2.19 & 28.24 & 0.97 & 4.16 & 4.24 \\
Mean & 11.09 & 1.38 & 29.21 & 0.31 & 2.36 & 7.61 \\
Std Dev & 16.82 & 0.33 & 0.96 & 0.19 & 0.94 & 4.52 \\
\hline & & & & & &
\end{tabular}

Table 3

Parameters of different land cover within the cooling distance.

\begin{tabular}{lcccc}
\hline \multirow{2}{*}{ Parameter } & \multicolumn{4}{c}{ Land cover } \\
\cline { 2 - 5 } & Bare land & Built-up & Forest & Cropland \\
\hline WCI_M $\left({ }^{\circ} \mathrm{C}\right)$ & 2.01 & 2.80 & 1.55 & 1.38 \\
Maximum LST difference $\left({ }^{\circ} \mathrm{C}\right)$ & 3.60 & 5.09 & 2.92 & 2.21 \\
WCI_G $\left({ }^{\circ} \mathrm{C} / \mathrm{km}\right)$ & 6.48 & 9.03 & 5.00 & 4.52 \\
\hline
\end{tabular}

The obtained results are similar to those of Cheval et al., who reported that the influence of lakes on the LST is $1-5^{\circ} \mathrm{C}$ depending on the land cover type. ${ }^{(40)}$ This difference can be explained by the different absorption rates of heat radiation for different types of land cover. Specifically, built-up land, mainly consisting of impervious surfaces, strongly absorbs heat from the sun. Bare land is mainly natural bare soil with strong water permeability, which has slightly higher thermal inertia and heat reflection ability than artificial impervious surfaces. ${ }^{(41)}$ Forest shows strong ability to reflect solar radiation owing to evapotranspiration and the shading effect. ${ }^{(42)}$ The cropland in the study area was mainly rice paddy fields. During summer, the evaporation of a large amount of water from rice paddy fields results in the absorption of a large amount of heat, which, combined with the large canopy of rice, gives cropland the lowest temperature among the different types of land cover.

WCI_G of the water bodies in the study area is between 4.24 and $20.6^{\circ} \mathrm{C} / \mathrm{km}$ with an average of $7.61{ }^{\circ} \mathrm{C} / \mathrm{km}$. The cooling gradient is also different for each land cover type. The maximum 

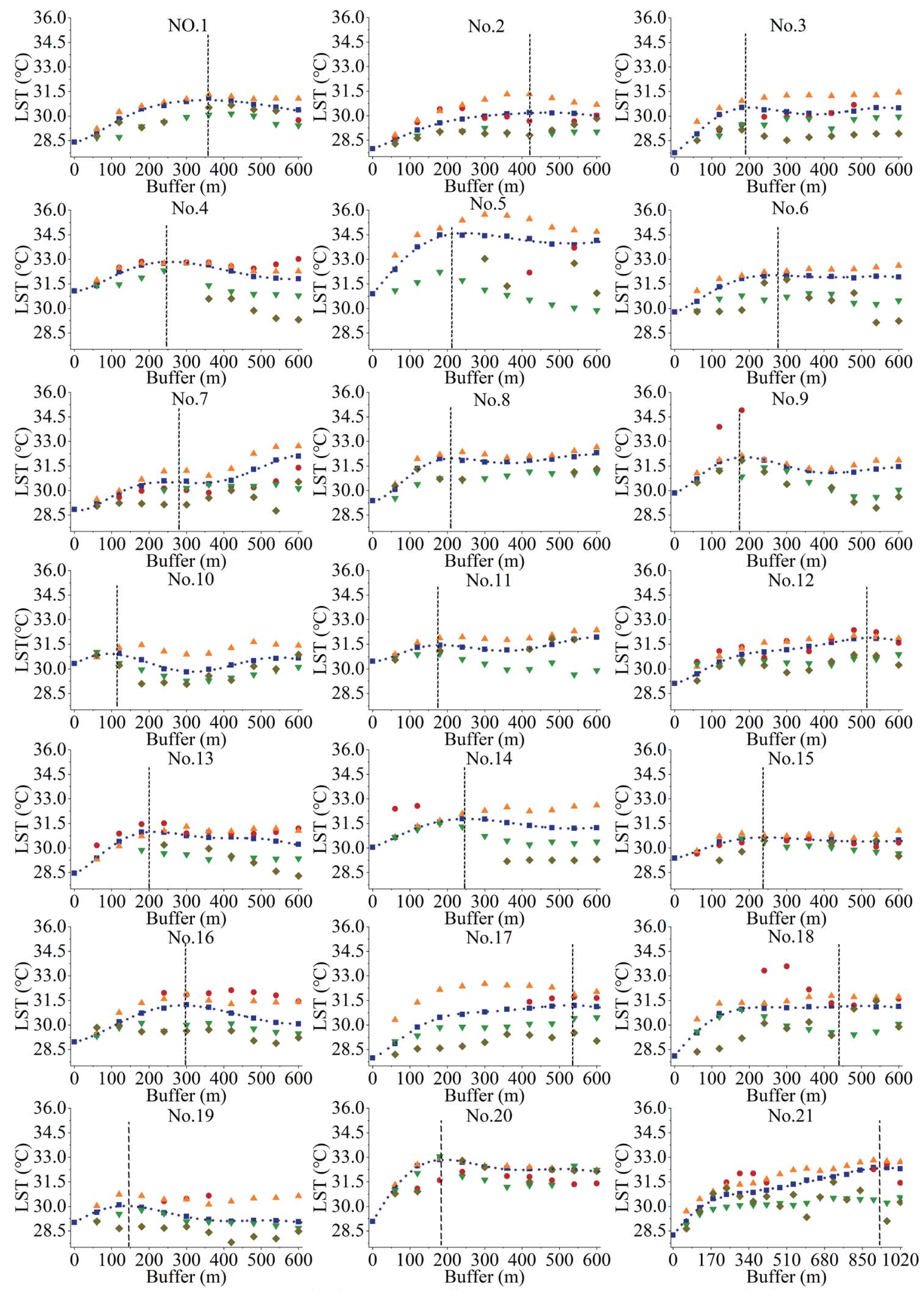

- LST - Bare land LST $\triangle$ Built-up LST - Forest LST - Cropland LST

Fig. 3. (Color online) LST curves of 21 water bodies. 
cooling gradient occurs in built-up $\left(9.03{ }^{\circ} \mathrm{C} / \mathrm{km}\right)$, followed by bare land $\left(6.48{ }^{\circ} \mathrm{C} / \mathrm{km}\right)$, forest $\left(5.00{ }^{\circ} \mathrm{C} / \mathrm{km}\right)$, and cropland $\left(4.52{ }^{\circ} \mathrm{C} / \mathrm{km}\right)$. This illustrates that the WCI effect has the strongest impact and the highest cooling efficiency on built-up land.

\subsection{Influence of landscape complexity of local environments on WCI effect}

\subsubsection{Influence of landscape indexes}

The correlation analysis suggests that several factors are relevant to the WCI effect (Table 4). The area of water bodies has a relatively strong positive relationship with WCI_D and WCI_M but no significant relationship with WCI_G. LSI also has a positive relationship with WCI_D but no obvious relationship with WCI_M and WCI_G. In addition, PD and SHDI were found to be negatively related to WCI_D and WCI_M but have little influence on WCI_G. PLAND_G and LPI_F has a negative correlation with WCI_G, while LPI_B and SPLIT_F have a positive correlation with WCI_G. AI_B and SPLIT_B show positive and negative relationships with WCI_M, respectively, and appear to be unrelated to WCI_D and WCI_G.

These results imply that WCI_D increases with increasing area, increasing complexity of the shape, decreasing landscape density, and decreasing SHDI. A larger water area has greater evapotranspiration of the water body, thereby increasing WCI_D. A more complex shape of the water body leads to a larger contact area between the water body and its surrounding environment, thereby increasing WCI_D. For a lower PD, a less heterogeneous landscape, and lower fragmentation of the landscape, the connection of green spaces is higher, then the absorption of solar radiation by the green spaces can effectively reduce the intensity and area of the heat island in the environment surrounding the water body, leading to an increase in WCI_D.

Table 4

Pearson correlation coefficient between influencing factors and WCI effect.

\begin{tabular}{lccc}
\hline \multirow{2}{*}{ Influencing factors } & \multicolumn{3}{c}{ WCI effect } \\
\cline { 2 - 4 } & WCI_D & WCI_M & WCI_G \\
\hline Water area & $0.7135^{*}$ & $0.6043^{*}$ & -0.0374 \\
\hline LSI & $0.5450^{*}$ & 0.3243 & -0.1556 \\
\hline PD & $-0.4738^{*}$ & $-0.6479^{*}$ & -0.1116 \\
\hline SHDI & $-0.5191^{*}$ & $-0.6697^{*}$ & -0.0891 \\
\hline PLAND_G & 0.1735 & -0.2592 & $-0.4844^{*}$ \\
\hline AI_BL & -0.2836 & 0.1092 & 0.3391 \\
\hline AI_C & -0.2174 & 0.0701 & 0.4312 \\
\hline AI_B & 0.3013 & $0.5267^{*}$ & 0.1426 \\
\hline AI_F & 0.0598 & -0.1600 & -0.2740 \\
\hline LPI_BL & -0.0336 & 0.0588 & 0.1050 \\
\hline LPI_C & -0.0393 & -0.1331 & -0.1741 \\
\hline LPI_B & -0.0146 & 0.4241 & $0.4437^{*}$ \\
\hline LPI_F & 0.1958 & -0.2727 & $-0.5035^{*}$ \\
\hline SPLIT_BL & 0.0960 & -0.0972 & -0.2232 \\
\hline SPLIT_C & -0.0869 & 0.0228 & 0.2090 \\
\hline SPLIT_B & -0.0868 & $-0.4385^{*}$ & -0.3412 \\
\hline SPLIT_F & -0.3927 & 0.0021 & $0.4387^{*}$ \\
\hline
\end{tabular}

$* p<0.05$ level 
WCI_M increases with increasing area, decreasing landscape density, decreasing SHDI, and a more concentrated and less separated built-up area. In general, a larger area results in a larger volume of the water body, which slows the temperature increase in the water body, thereby causing an obvious temperature difference between the water body and its surrounding area. WCI_M increases with decreasing proportion of green space, increasing proportion of the largest patch in the built-up area, decreasing proportion of the largest patch in the forest, and a more separated forest. For a smaller PD, a smaller SHDI, lower fragmentation of the landscape, and higher ratio and connectivity of green spaces, the solar radiation absorbed by the green spaces and their shading effects reduce the rate of warming of the water body, thereby increasing WCI_M. For a more concentrated and less separated built-up area, the higher temperature in the built-up area aggravates the UHI effect, thereby increasing WCI_M.

WCI_G increases with decreasing green space ratio, increasing proportion of the largest patch belonging to the built-up area, decreasing proportion of forest, and less clustered forest. These conditions all increase the ambient temperature in the water body, leading to a more obvious thermal environment issue and an increase in WCI_G.

The key influencing factors in the landscape on the WCI effect were selected by stepwise regression analysis (Table 5). Generally, all the built models showed a relatively acceptable explanation rate $(>44 \%)$.

SHDI (-), AI_BL (-), and PLAND_G (+) contributed significantly to the prediction of WCI_D. A lower SHDI means fewer landscape types, a lower degree of patch fragmentation, and greater connectivity of the landscape. A lower AI_BL means a lower concentration of bare land. A larger PLAND_G means a higher proportion of green spaces. WCI_D increases with decreasing patch fragmentation, decreasing concentration of bare land, and a higher percentage of green spaces. This is due to the ability of green spaces to absorb solar radiation. The green space patches effectively break up impervious surfaces, thereby reducing the intensity and area of the heat island and increasing WCI_D. ${ }^{(43)}$ This finding is consistent with previous studies, which found that larger and more continuous green spaces surrounding a water body achieve a better cold island effect. ${ }^{(15,44)}$

The most relevant factors influencing WCI_M are LSI $(-)$, AI_B (+), water area $(+)$, and PD $(-)$. A water body with a simple shape has a smaller contact area with its surroundings. A more concentrated built-up area increases the UHI effect, contributing to an increase in the LST. A larger area of water body has a lower LST in the water body. A smaller PD indicates a lower degree of fragmentation, changing the ambient temperature in the water body. These conditions all contribute to increasing the temperature difference between the water body and its surrounding environment, thereby increasing WCI_M.

Table 5

Stepwise regression models for the key factors affecting the WCI effect.

\begin{tabular}{lcc}
\hline WCI effect & Coefficients & $R^{2}$ \\
\hline WCI_D & SHDI $\left(-2.3716^{* *}\right)$, AI_BL $\left(-0.0451^{*}\right)$, PLAND_G $\left(0.0089^{*}\right)$ & 0.7321 \\
WCI_M & LSI $\left(-1.4008^{*}\right)$, AI_B $(0.1422)$, water area $\left(0.0368^{*}\right)$, PD $(-0.0189)$ & 0.7553 \\
WCI_G & SHDI $(15.4979)$, AI_F $(-1.8788)$, LPI_B $\left(0.2881^{* *}\right)$ & 0.4417
\end{tabular}

Standardized coefficients were used to determine the relative importance of the explanatory variables, and larger absolute values of the standardized coefficients indicate higher importance in predicting the WCI effect.

$* * p<0.01$ level; $* p<0.05$ level; Others $p<0.1$ level 
The factors with the greatest impact on WCI_G are SHDI (+), AI_F (-), and LPI_B (+), indicating that a water body in a dense urban area has the capacity to achieve the highest cooling efficiency. A higher SHDI means a higher rate of land use, higher heterogeneity, and a more fragmented landscape, leading to an increase in the LST. A less clustered forest with poor connectivity of the forest also increases the LST, which, combined with the larger LPI_B, aggravates the UHI effect, thereby increasing WCI_G.

\subsubsection{Influence of wind direction on WCI effect}

Table 6 gives the WCI effect of the 21 water bodies for different wind directions. WCI_D is largest $(0.29 \mathrm{~km})$ in the N-NE and W-NW directions and smallest $(0.22 \mathrm{~km})$ in the S-SW direction. The largest WCI_M $\left(2.71{ }^{\circ} \mathrm{C}\right)$ occurs in the E-SE direction, followed by the S-SW direction $\left(2.61{ }^{\circ} \mathrm{C}\right)$, N-NE direction $\left(2.42{ }^{\circ} \mathrm{C}\right)$, and $\mathrm{W}-\mathrm{NW}$ direction $\left(2.16^{\circ} \mathrm{C}\right)$. The greatest WCI_G appears in the S-SW direction, followed by the E-SE, N-NE, and W-NW directions.

To illustrate the influence of the wind direction on the WCI effect, the water bodies with simple terrain (i.e., excluding those surrounded by mountains or built-up area) were selected. As shown in Fig. 4, in the upwind direction of the prevailing wind, the average WCI_D, WCI_M, and WCI_G are $0.21 \mathrm{~km}, 2.31{ }^{\circ} \mathrm{C}$, and $10.75{ }^{\circ} \mathrm{C} / \mathrm{km}$, compared with $0.36 \mathrm{~km}, 2.55{ }^{\circ} \mathrm{C}$, and $7.61{ }^{\circ} \mathrm{C} / \mathrm{km}$ in the downwind direction of the prevailing wind, respectively. WCI_D and WCI_M

Table 6

Influence of wind direction on WCI effect.

\begin{tabular}{|c|c|c|c|c|c|c|c|c|c|c|c|c|}
\hline \multirow{3}{*}{$\begin{array}{l}\text { WCI } \\
\text { effect } \\
\text { Water } \\
\text { number }\end{array}$} & \multicolumn{4}{|c|}{ WCI_D (km) } & \multicolumn{4}{|c|}{ WCI_M $\left({ }^{\circ} \mathrm{C}\right)$} & \multicolumn{4}{|c|}{ WCI_G $\left({ }^{\circ} \mathrm{V} / \mathrm{km}\right)$} \\
\hline & \multicolumn{4}{|c|}{ Direction } & \multicolumn{4}{|c|}{ Direction } & \multicolumn{4}{|c|}{ Direction } \\
\hline & N-NE & E-SE & S-SW & W-NW & N-NE & E-SE & S-SW & W-NW & N-NE & E-SE & S-SW & W-NW \\
\hline 1 & 0.38 & 0.34 & 0.16 & 0.18 & 3.19 & 2.84 & 1.27 & 2.85 & 8.41 & 8.36 & 7.91 & 15.84 \\
\hline 2 & 0.33 & 0.42 & 0.15 & 0.17 & 2.97 & 2.84 & 3.04 & 1.16 & 8.99 & 6.77 & 20.24 & 6.80 \\
\hline 3 & 0.18 & 0.18 & 0.17 & 0.36 & 3.09 & 2.06 & 2.27 & 3.42 & 17.18 & 11.46 & 13.33 & 9.50 \\
\hline 4 & 0.15 & 0.25 & 0.32 & 0.24 & 1.69 & 1.81 & 2.55 & 1.60 & 11.25 & 7.25 & 7.96 & 6.65 \\
\hline 5 & 0.40 & 0.30 & 0.17 & 0.18 & 3.62 & 8.32 & 3.92 & 1.74 & 9.04 & 27.74 & 23.07 & 9.66 \\
\hline 6 & 0.45 & 0.17 & 0.18 & 0.30 & 2.44 & 2.25 & 2.80 & 2.79 & 5.42 & 13.24 & 15.54 & 9.29 \\
\hline 7 & 0.18 & 0.27 & 0.65 & 0.28 & 0.73 & 3.53 & 3.25 & 1.59 & 4.06 & 13.07 & 5.00 & 5.66 \\
\hline 8 & 0.65 & 0.22 & 0.16 & 0.18 & 5.70 & 2.95 & 2.67 & 1.71 & 8.78 & 13.42 & 16.71 & 9.47 \\
\hline 9 & 0.15 & 0.12 & 0.18 & 0.20 & 1.70 & 1.56 & 3.09 & 3.00 & 11.33 & 13.00 & 17.19 & 15.01 \\
\hline 10 & 0.07 & 0.1 & 0.13 & 0.15 & 0.28 & 0.66 & 0.88 & 1.22 & 4.03 & 6.60 & 6.75 & 8.16 \\
\hline 11 & 0.14 & 0.17 & 0.18 & 0.21 & 0.71 & 1.06 & 1.14 & 1.45 & 5.08 & 6.24 & 6.33 & 6.91 \\
\hline 12 & 0.53 & 0.20 & 0.36 & 0.54 & 2.83 & 1.96 & 3.41 & 2.01 & 5.34 & 9.81 & 9.47 & 3.73 \\
\hline 13 & 0.24 & 0.19 & 0.17 & 0.31 & 2.84 & 2.44 & 2.55 & 2.74 & 11.85 & 12.82 & 14.97 & 8.84 \\
\hline 14 & 0.42 & 0.28 & 0.12 & 0.19 & 2.41 & 3.1 & 1.94 & 1.04 & 5.74 & 11.07 & 16.21 & 5.47 \\
\hline 15 & 0.14 & 0.26 & 0.28 & 0.39 & 1.62 & 1.13 & 2.03 & 1.88 & 11.59 & 4.34 & 7.24 & 4.81 \\
\hline 16 & 0.28 & 0.36 & 0.38 & 0.18 & 3.49 & 2.46 & 2.74 & 0.48 & 12.46 & 6.82 & 7.20 & 2.64 \\
\hline 17 & 0.54 & 0.36 & 0.20 & 0.53 & 2.11 & 4.86 & 4.03 & 2.38 & 3.91 & 13.50 & 20.14 & 4.49 \\
\hline 18 & 0.37 & 0.36 & 0.18 & 0.48 & 3.00 & 3.48 & 3.04 & 3.62 & 8.10 & 9.68 & 16.86 & 7.55 \\
\hline 19 & 0.11 & 0.16 & 0.13 & 0.14 & 0.14 & 1.19 & 1.62 & 1.43 & 1.32 & 7.44 & 12.49 & 10.24 \\
\hline 20 & 0.18 & 0.24 & 0.18 & 0.18 & 3.70 & 3.57 & 4.05 & 2.8 & 20.56 & 14.87 & 22.52 & 15.54 \\
\hline 21 & 0.24 & 0.18 & 0.23 & 0.60 & 2.63 & 2.74 & 2.51 & 4.44 & 10.95 & 15.24 & 10.93 & 7.40 \\
\hline Mean & 0.29 & 0.24 & 0.22 & 0.29 & 2.42 & 2.71 & 2.61 & 2.16 & 8.30 & 11.08 & 11.71 & 7.57 \\
\hline
\end{tabular}




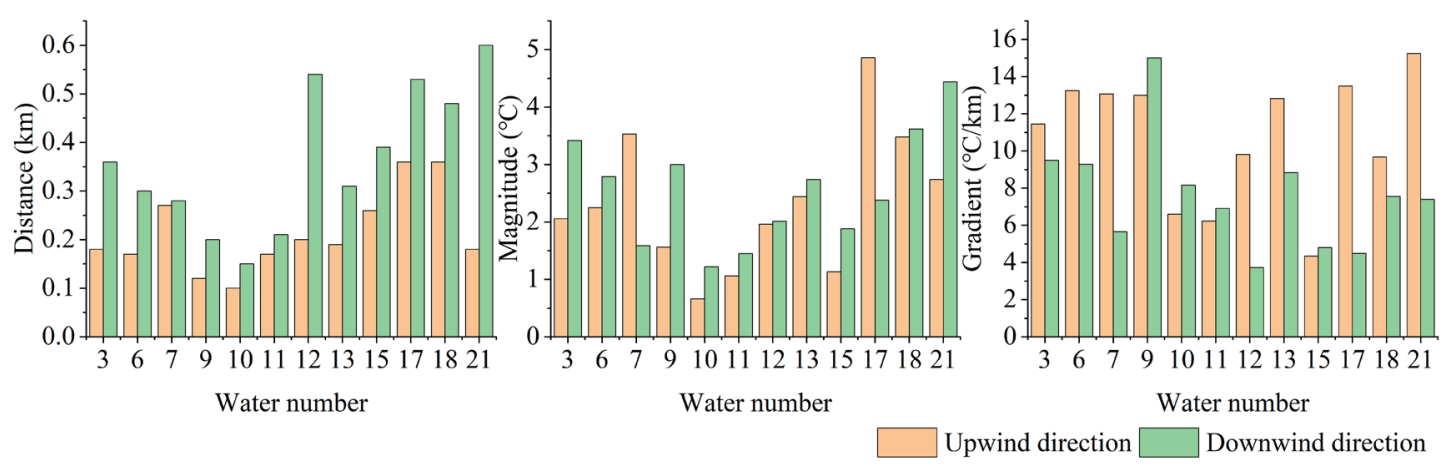

Fig. 4. (Color online) WCI effects of water bodies with simple terrain.

are considerably higher in the downwind direction than in the upwind direction, implying that the wind direction has significant impact on the WCI effect. This is similar to the results of Gupta et al., who demonstrated that air ducts can effectively mitigate the UHI effect. ${ }^{(45)}$

\subsection{Implications and limitations}

\subsubsection{Implications for urban planning of impacts of local environment on WCI effect}

There are three recommendations for the design of water bodies and surrounding areas: (1) a water body with a reasonable configuration can produce a good cooling effect on the surrounding environment as part of urban planning. Preventing the expansion and infiltration of built-up and bare land and increasing the green space around the water body as much as possible to form a continuous and concentrated blue-green space will increase its cooling effect. (2) For the centers of urban areas with a high building density and high plot ratio, water bodies can be established in combination with urban parks and residential blocks to form a blue-green land network, reduce the concentration of impervious ground, and alleviate the internal UHI effect. (3) Green spaces should be configured in combination with urban air ducts. For example, configuring more continuous green spaces in the upward wind direction of the prevailing wind surrounding the water body will achieve a better WCI effect. The findings of this study could provide some useful guidelines in the future urban planning of other countries and regions with similar terrain and climate to Changsha, although the WCI effect will be slightly different.

\subsubsection{Limitations}

We concentrated on the impacts of the local environment on the WCI effect and extracted the main influencing factors by stepwise regression analysis. The influence of the wind speed and wind direction on the WCI effect was presented; however, it was not quantified in the model. Moreover, other factors including building heights and topographic parameters could influence the wind speed and direction. ${ }^{(46)}$ Therefore, more factors should be added in the future to improve the existing model. 
Previous studies have shown that the WCI effect varies considerably between day and night and among the four seasons. ${ }^{(37,46-48)}$ This was not investigated in our study because of the limited Landsat data. The local environment surrounding water bodies will markedly change with the growth and decay of vegetation during the four seasons; therefore, seasonal and diurnal changes in the WCI effect should be examined in the future.

\section{Conclusions}

The UHI effect has become a serious threat to the urban ecology, causing great harm to the health of urban residents and the sustainable development of the ecological environment. We investigated the WCI effect of 21 water bodies in Changsha and revealed the relationship between the WCI effect and various influencing factors. The conclusions are summarized as follows.

The water body has a certain cold island effect. For the 21 water bodies in the study area, WCI_D is between 0.12 and $0.97 \mathrm{~km}$ with an average of $0.31 \mathrm{~km}$, WCI_M is between 0.64 and $4.16^{\circ} \mathrm{C}$ with an average of $2.36{ }^{\circ} \mathrm{C}$, and WCI_G is between 4.24 and $20.6{ }^{\circ} \mathrm{C} / \mathrm{km}$ with an average of $7.61{ }^{\circ} \mathrm{C} / \mathrm{km}$. For areas with abundant water resources, we recommend the mitigation of the UHI effect by preserving natural water bodies and adding artificial lakes as part of urban planning.

Different types of land cover contribute to markedly different increases in the LST. Built-up land has the largest increase of $2.80{ }^{\circ} \mathrm{C}$, followed by bare land $\left(2.01{ }^{\circ} \mathrm{C}\right)$, forest $\left(1.55^{\circ} \mathrm{C}\right)$, and cropland $\left(1.38^{\circ} \mathrm{C}\right)$. This indicates that water bodies in dense urban areas provide a good cooling effect.

The WCI effect is affected by multiple indicators. For WCI_D, the largest influencing factor is SHDI (-), followed by AI_BL (-) and PLAND_G (+); for WCI_M, the largest influencing factor is LSI $(-)$, followed by AI_B $(+)$, water area $(+)$, and PD $(-)$; for WCI_G, the main factors are SHDI $(+)$, AI_F $(-)$, and LPI_B $(+)$. Therefore, the design of water bodies should include a surrounding forest landscape to obtain a greater WCI effect.

The wind direction has a significant impact on WCI_D and WCI_M. In the case of a simple local environment, in the upwind direction of the prevailing wind, WCI_D is $0.1-0.36 \mathrm{~km}$ with an average of $0.21 \mathrm{~km}$ and WCI_M is $0.66-4.86{ }^{\circ} \mathrm{C}$ with an average of $2.31{ }^{\circ} \mathrm{C}$. In the downwind direction of the prevailing wind, WCI_D is $0.2-0.6 \mathrm{~km}$ with an average of $0.36 \mathrm{~km}$ and WCI_M is $1.22-4.44{ }^{\circ} \mathrm{C}$ with an average of $2.55^{\circ} \mathrm{C}$. Therefore, the design of a water body should take the wind direction and path into account, and the water body should be combined with surrounding green spaces to maximize the WCI effect.

\section{Acknowledgments}

This research was conducted with the support of the Korea Environment Industry \& Technology Institute (KEITI) through its Urban Ecological Health Promotion Technology Development Project, and funded by the Korea Ministry of Environment (MOE) (2019002760001). 


\section{References}

1 P. Xiao, X. Wang, X. Feng, X. Zhang, and Y. Yang: IEEE J. Selected Topics Appl. Earth Observ. Remote Sens. 7 (2014) 4095. https://doi.org/10.1109/JSTARS.2014.2302855

2 National Bureau of Statistics: http://www.stats.gov.cn/ (accessed 24 May 2021).

3 Z. W. Yu, G. Y. Yang, S. D. Zuo, G. Jorgensen, M. Koga, and H. Vejre: Urban For. Urban Green. 49 (2020) 126630. https://doi.org/10.1016/j.ufug.2020.126630

4 M. F. Abdulateef and H. A. Al-Alwan: Ain Shams Eng. J. (2021). https://doi.org/doi.org/10.1016/j. asej.2021.06.012

5 L. Chen, X. L. Wang, X. B. Cai, C. Yang, and X. R. Lu: Remote Sens. 13 (2021) 323. https://doi.org/10.3390/ rs13020323

6 Z. Wu and Y. Zhang: Sustainability 11 (2019) 787. https://doi.org/10.3390/su11030787

7 J. S. Wilson, M. Clay, E. Martin, D. Stuckey, and K. Vedder-Risch: Remote Sens. Environ. 86 (2003) 303. http://doi.org/10.1016/S0034-4257(03)00084-1

8 M. Hart and D. Sailor: Theor. Appl. Climatol. 95 (2009) 397. https://doi.org/10.1007/s00704-008-0017-5

9 X. Y. Xu, S. M. Liu, S. B. Sun, W. W. Zhang, Y. Liu, Z. M. Lao, G. C. Guo, K. Smith, Y. Cui, W. Liu, E. H. Garcia, and J. N. Zhu: Energy Build. 188 (2019) 58. https://doi.org/10.1016/j.enbuild.2019.02.003

10 C. A. Hossu, I. C. Ioja, D. A. Onose, M. R. Nita, A. M. Popa, O. Talaba, and L. Inostroza: Ecosyst. Serv. 37 (2019) 100937. http://doi.org/10.1016/j.ecoser.2019.100937

11 Z. Zeng, X. Zhou, and L. Li: Procedia Eng. 205 (2017) 2034. https://doi.org/10.1016/j.proeng.2017.10.082

12 R. Sun and L. Chen: Landscape Urban Plann. 105 (2012) 27. https://doi.org/10.1016/j.landurbplan.2011.11.018

13 A. M. Broadbent, A. M. Coutts, N. J. Tapper, M. Demuzere, and J. Beringer: Theor. Appl. Climatol. 134 (2018) 1. https://doi.org/10.1007/s00704-017-2241-3

14 C. Jacobs, L. Klok, M. Bruse, J. Cortesão, S. Lenzholzer, and J. Kluck: Urban Clim. 32 (2020) 100607. https:// doi.org/10.1016/j.uclim.2020.100607

15 H. Y. Du, X. J. Song, H. Jiang, Z. H. Kan, Z. B. Wang, and Y. L. Cai: Ecol. Indic. 67 (2016) 31. https://doi. org/10.1016/j.ecolind.2016.02.040

16 K. Yu, Y. Chen, L. Liang, A. Gong, and J. Li: Sci. Total Environ. 727 (2020) 138750. https://doi.org/10.1016/j. scitotenv.2020.138750

17 N. I. Syafii, M. Ichinose, N. H. Wong, E. Kumakura, S. K. Jusuf, and K. Chigusa: Procedia Eng. 169 (2016) 191. https://doi.org/10.1016/j.proeng.2016.10.023

18 H. Saaroni and B. Ziv: Int. J. Biometeorol. 47 (2003) 156. https://doi.org/10.1007/s00484-003-0161-7

19 L. M. Adams and L. E. Dove: A Guide to Ecological Landscape Planning and Resource Conservation (Maryland, US: National Institute for Urban Wildlife, Columbia, MD, USA, 1989).

20 Z. Qiao, L. Liu, Y. W. Qin, X. L. Xu, B. W. Wang, and Z. J. Liu: Remote Sens. 12 (2020) 794. https://doi.org/ ARTN79410.3390/rs12050794

21 Z. Dai, J. M. Guldmann, and Y. Hu: Sci. Total Environ. 626 (2018) 1136. https://doi.org/10.1016/j. scitotenv.2018.01.165

22 Y. Yu, Q. Jian-xin, and H. Shun-shi: J. Geo-Inf. Sci. 4 (2017) 518. https://doi.org/10.3724/SP.J.1047.2017.00518

23 China Meteorological Data Service Center: https://data.cma.cn/ (accessed 5 June 2021).

24 S.-H. K. Xinyi Qiu and C. Park: Sens. Mater. (2021) (in press).

25 V. Caselles, E. Rubio, C. Coll, and E. Valor: J. Geophys. Res.: Atmos. 103 (1998) 17057. https://doi. org/10.1029/98JD01480

26 J. R. Irons, J. L. Dwyer, and J. A. Barsi: Remote Sens. Environ. 122 (2012) 11. https://doi.org/10.1016/j. rse.2011.08.026

27 J. A. Barsi, J. R. Schott, S. J. Hook, N. G. Raqueno, B. L. Markham, and R. G. Radocinski: Remote Sens. 6 (2014) 11607. https://doi.org/10.3390/rs61111607

28 M. Montanaro, A. Gerace, A. Lunsford, and D. Reuter: Remote Sens. 6 (2014) 10435. https://doi.org/10.3390/ rs61110435

29 S.-H. Kil: KIEAE J. 17 (2017) 63. https://doi.org/10.12813/kieae.2017.17.6.06

30 F. H. Kong, H. W. Yin, P. James, L. R. Hutyra, and H. S. He: Landscape Urban Plann. 128 (2014) 35. https://doi. org/10.1016/j.landurbplan.2014.04.018

31 F. Wang, Z. H. Qin, C. Y. Song, L. L. Tu, A. Karnieli, and S. H. Zhao: Remote Sens. 7 (2015) 4268. https://doi. org $/ 10.3390 / \mathrm{rs} 70404268$

32 A. M. Rizwan, L. Y. Dennis, and L. Chunho: J. Environ. Sci. 20 (2008) 120.

33 F. Musco: Counteracting Urban Heat Island Effects in a Global Climate Change Scenario (Springer Nature, 2016). https://doi.org/10.1007\%2F978-3-319-10425-6 
34 W. Lahmer, B. Pfützner, and A. Becker: Phys. Chem. Earth B 26 (2001) 565. https://doi.org/10.1016/S14641909(01)00051-X

35 R. Sun, A. Chen, L. Chen, and Y. Lü: Ecol. Indic. 20 (2012) 57. https://doi.org/10.1016/j.ecolind.2012.02.006

36 A. Chen, L. Yao, R. Sun, and L. Chen: Ecol. Indic. 45 (2014) 424. https://doi.org/10.1016/j.ecolind.2014.05.002

37 L. Yao, T. Li, M. X. Xu, and Y. Xu: Urban For. Urban Green. 52 (2020) 126704. https://doi.org/10.1016/j. ufug.2020.126704

38 R. H. Sun, Y. H. Lu, L. D. Chen, L. Yang, and A. L. Chen: Build. Environ. 65 (2013) 90. https://doi.org/10.1016/j. buildenv.2013.04.001

39 L. Yao, W. Wei, and L. Chen: Ecol. Indic. 60 (2016) 893. https://doi.org/10.1016/j.ecolind.2015.08.041

40 S. Cheval, A. M. Popa, I. Sandric, and I. C. Ioja: Urban Clim. 34 (2020) 100696. https://doi.org/10.1016/j. uclim.2020.100696

41 Q. Weng: Int. J. Remote Sens. 22 (2010) 1999. https://doi.org/10.1080/713860788

42 X. Cao, A. Onishi, J. Chen, and H. Imura: Landscape Urban Plann. 96 (2010) 224. https://doi.org/10.1016/j. landurbplan.2010.03.008

43 W. Q. Zhou, Y. G. Qian, X. M. Li, W. F. Li, and L. J. Han: Landscape Ecol. 29 (2014) 153. https://doi. org/10.1007/s10980-013-9950-5

44 T. Mostofa and G. Manteghi: Int. Tran. J. Eng. Manage. Appl. Sci. Technol. 11 (2020) 1. https://doi.org/10.14456/ Itjemast.2020.27

45 N. Gupta, A. Mathew, and S. Khandelwal: Egypt. J. Remote Sens. Space. Sci. 22 (2019) 81. https://doi. org/10.1016/j.ejrs.2018.03.007

46 C. Y. Park, D. K. Lee, T. Asawa, A. Murakami, H. G. Kim, M. K. Lee, and H. S. Lee: Landscape Urban Plann. 183 (2019) 26. https://doi.org/10.1016/j.landurbplan.2018.10.022

47 R. Spronken-Smith and T. Oke: Boundary Layer Meteorol. 93 (1999) 287. https://doi. org/10.1023/A:1002001408973

48 C. R. Chang and M. H. Li: Urban For. Urban Green. 13 (2014) 672. https://doi.org/10.1016/j.ufug.2014.08.001

\section{About the Authors}

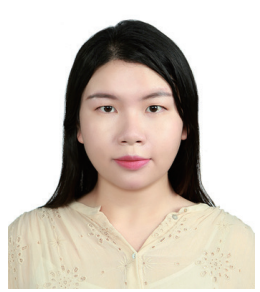

Xinyi Qiu is a Ph.D. candidate in the Department of Landscape Architecture, Kangwon National University, South Korea. Her research interests include urban thermal environments and ecological investigation using remote sensing of satellite images. (qiuxinyi@kangwon.ac.kr)

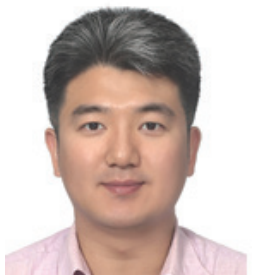

Sung-Ho Kil is an assistant professor at Kangwon National University. He graduated from Kangwon National University in 2003, majoring in landscape architecture. He earned his MLA and Ph.D. degrees from Seoul National University in 2007 and 2014, respectively. His research interests include ecological restoration, spatial ecology, and landscape ecology.

(sunghokil@kangwon.ac.kr)

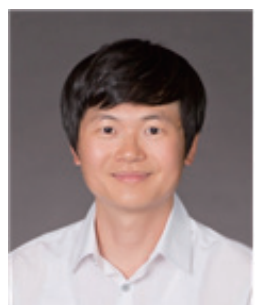

Chan Park is an associate professor at University of Seoul. He graduated from Seoul National University in 2007, majoring in landscape architecture. He earned his MLA and Ph.D. degrees from Seoul National University in 2009 and 2012, respectively. His research interests include climate change, social behavior, and spatial informatics. (chaneparkmomo7@uos.ac.kr) 